\title{
Long-term and delayed functional recovery in patients with severe cerebrovascular and traumatic brain injury requiring tracheostomy
}

\author{
Rafael Wabl, MD, ${ }^{2}$ Craig A. Williamson, MD, ${ }^{1,2}$ Aditya S. Pandey, MD, ${ }^{1}$ and \\ Venkatakrishna Rajajee, MBBS ${ }^{1,2}$
}

Departments of ${ }^{1}$ Neurosurgery and ${ }^{2}$ Neurology, University of Michigan, Ann Arbor, Michigan

OBJECTIVE Data on long-term functional recovery (LFR) following severe brain injury are essential for counseling of surrogates and for appropriate timing of outcome assessment in clinical trials. Delayed functional recovery (DFR) beyond 3-6 months is well documented following severe traumatic brain injury (STBI), but there are limited data on DFR following severe cerebrovascular brain injury. The objective of this study was to assess LFR and DFR in patients with STBI and severe stroke dependent on tracheostomy and tube feeding at the time of discharge from the intensive care unit (ICU).

METHODS The authors identified patients entered into their tracheostomy database 2008-2013 with sTBI and severe stroke, encompassing SAH, intracerebral hemorrhage (ICH), and acute ischemic stroke (AIS). Eligibility criteria included disease-specific indicators of severity, Glasgow Coma Scale score $<9$ at time of tracheostomy, and need for tracheostomy and tube feeding at ICU discharge. Assessment was at 1-3 months, 6-12 months, 12-24 months, and 24-36 months after initial injury for presence of tracheostomy, ability to walk, and ability to perform basic activities of daily living (B-ADLs). Long-term functional recovery (LFR) was defined as recovery of the ability to walk or perform B-ADLs by the 24- to 36-month follow-up. Delayed functional recovery (DFR) was defined as progression in functional milestones between any 2 time points beyond the 1 - to 3 -month follow-up.

RESULTS A total of 129 patients met the eligibility criteria. Functional outcomes were available for $129(100 \%), 97$ $(75 \%), 83(64 \%)$, and $80(62 \%)$ patients, respectively, from assessments at 1-3, 6-12, 12-24 and 24-36 months; 33 (26\%) died by $24-36$ months. Fifty-nine (46\%) regained the ability to walk and $48(37 \%)$ performed B-ADLs at some point during their recovery. Among survivors who had not achieved the respective milestone at $1-3$ months, $29 / 58(50 \%)$ were able to walk and 28/74 (38\%) performed B-ADLs at 6-12 months. Among survivors who had not achieved the respective milestone at 6-12 months, $5 / 16(31 \%)$ were able to walk and 13/30 (43\%) performed B-ADLs at 12-24 months. There was no significant difference in rates of LFR or DFR between patients with STBI and those with severe stroke.

CONCLUSIONS Among patients with severe brain injury requiring tracheostomy and tube feeding at ICU discharge, $46 \%$ regained the ability to walk and $37 \%$ performed B-ADLs $2-3$ years after injury. DFR beyond $1-3$ and $6-12$ months was seen in over $30 \%$ of survivors, with no significant difference between sTBI and severe stroke.

https://thejns.org/doi/abs/10.3171/2018.2.JNS173247

KEYWORDS acute brain injury; traumatic brain injury; stroke; tracheostomy; activities of daily living; trauma; vascular disorders

$\mathrm{B}$ RAIN injury caused by cerebrovascular disease, encompassing acute ischemic stroke (AIS), intracerebral hemorrhage (ICH), and subarachnoid hemorrhage (SAH), is a leading cause of long-term disability in the United States, with an estimated prevalence of about 6.8 million cases among adult Americans. ${ }^{9}$ Traumatic brain injury (TBI) is another important cause of functional impairment, with an estimated US prevalence of TBI-related long-term disability of about 3.32 million. ${ }^{36}$ Over $40 \%$ of patients hospitalized with TBI in

ABBREVIATIONS AIS = acute ischemic stroke; B-ADL = basic activity of daily living; $\mathrm{Cl}=$ confidence interval; $\mathrm{DFR}=$ delayed functional recovery; FIM = Functional Independence Measure; GCS = Glasgow Coma Scale; GOS = Glasgow Outcome Scale; ICH = intracerebral hemorrhage; ICU = intensive care unit; IQR = interquartile range; LFR = long-term functional recovery; mRS = modified Rankin Scale; NIHSS = National Institutes of Health Stroke Scale; OR = odds ratio; SAH = subarachnoid hemorrhage; $\mathrm{STBI}=$ severe $\mathrm{TBI} ; \mathrm{TBI}=$ traumatic brain injury.

SUBMITTED December 30, 2017. ACCEPTED February 23, 2018.

INCLUDE WHEN CITING Published online July 6, 2018; DOI: 10.3171/2018.2.JNS173247. 
the United States in 2003 were left with long-term disability. ${ }^{30}$ There are relatively limited data on long-term functional recovery (LFR) in survivors of severe brain injury of any cause who require intensive care unit (ICU) admission and remain dependent on an artificial airway and tube feeding at the time of discharge from the ICU. This is significant because of a common perception that these patients are unlikely to attain a meaningful longterm recovery. ${ }^{10,18}$ More recent studies of patients in the most severe strata of injury, including "poor-grade" SAH, suggest that a significant number may in fact attain a good LFR. ${ }^{11,17,24,35}$ A major potential confounder in some of these studies, however, is the influence of early reversible factors such as hydrocephalus, residual sedation following intubation, and seizures at onset, which may result in overestimation of the initial severity of injury. ${ }^{34}$ Up to $30 \%$ of SAH patients classified as "poor grade" at admission may rapidly improve by at least 1 grade prior to surgery, following early ventricular drainage. ${ }^{28}$ Contemporary data are essential for appropriate counseling of surrogate decision makers. Our primary aim, therefore, was to describe the trajectory of functional recovery over a 3-year period in a contemporary setting, in patients with severe brain injury, of both cerebrovascular and traumatic etiology, who did not demonstrate rapid neurological improvement following admission and required tracheostomy and artificial enteral nutrition at the time of ICU discharge.

The time period over which recovery may occur is also of critical importance. While most deaths following withdrawal of life-sustaining therapy occur in the ICU within 7 days of brain injury, ${ }^{22,32}$ it is not clear that an individual's full potential for recovery can be reliably estimated during this time. The phenomenon of delayed functional recovery (DFR), with progression in functional recovery milestones beyond 3-6 months, is well documented following severe TBI (sTBI). 1,11,13,17,19,21,25,29,31 There are, however, relatively limited published data on the incidence of DFR - and time taken to reach specific milestones of recovery-following severe stroke. ${ }^{17,23,24,35}$ Such information also guides the determination of appropriate time points for outcome assessment in clinical trials, which is typically performed $1-3$ months after stroke, $, 3,7,20,26$ as against 6-12 months after sTBI, where DFR is expected., ${ }^{4,6,14}$ Delayed recovery beyond the time point of outcome assessment may not be captured, resulting in an incomplete assessment of the benefit of an intervention. ${ }^{11,35}$ An additional goal of this study was, therefore, to examine the incidence of DFRthe recovery of significant functional milestones beyond 3-12 months -in patients in the most severe strata of cerebrovascular injury and compare the findings to the incidence in STBI.

Our specific objectives were to 1) describe rates, and the trajectory, of LFR to specific endpoints-tracheostomy decannulation, the ability to walk, and the ability to perform basic activities of daily living (B-ADLs) - over a period of 2-3 years, in patients in the most severe strata of brain injury requiring tracheostomy and tube feeding at ICU discharge; and 2) compare DFR beyond 3-12 months among patients with cerebrovascular brain injury (SAH, ICH, and AIS) and sTBI.

\section{Methods}

Approval for this study was obtained from the University of Michigan institutional review board.

\section{Eligibility Criteria}

We included patients with sTBI, SAH, ICH, and AIS entered into our neurointensive-care tracheostomy database over a 5-year period (2008-2013). Injury severity was established by: a) disease-specific indicator of severity the time of admission: Glasgow Coma Scale (GCS) score < 9 for sTBI, Hunt and Hess grade $>3$ for SAH, National Institutes of Health Stroke Scale (NIHSS) score $>15$ for AIS, and ICH score $>2$ plus NIHSS score $>15$ for ICH; b) need for tracheostomy; c) GCS score $<9$ at the time of tracheostomy, and d) requirement for tracheostomy and artificial enteral nutrition at the time of ICU discharge. Patients who underwent tracheostomy were selected to avoid including patients whose initial severity may have been overestimated because of early reversible factors and to identify patients whose surrogates were likely committed to the provision of supportive care beyond the ICU stay. Patients were also required to have a GCS score $<9$ off sedation at the time of tracheostomy; the purpose of this requirement was to select patients who required the procedure for their neurological disability and impaired consciousness rather than exclusively for respiratory reasons. The presence of significant respiratory failure was not an exclusion criterion, however, in patients with a GCS score $<9$ off sedation at the time of the procedure. Patients with less than 1 month of follow-up were excluded. We included patients with 1 month of follow-up to capture subjects with unexpectedly rapid improvements in functional ability.

\section{Data Source}

The purpose of the tracheostomy quality-control database, established in 2008, was to track short- and longterm complications of all tracheostomies performed in the neuro-ICU. ${ }^{27}$ Information on demographics, baseline disease severity, timing and type of tracheostomy (surgical vs percutaneous), individual performing the tracheostomy, short- and long-term complications, and tracheostomy decannulation was prospectively entered.

\section{Tracheostomy Timing and Follow-Up}

Timing of tracheostomy was at the discretion of the attending physician. Although a specific protocol was not in use, clinical practice favored performance of tracheostomy toward the end of the 1st week in patients judged likely to require an artificial airway for more than 3 weeks. This time period was considered sufficient to clarify the effect of easily reversible factors such as hydrocephalus, seizure at onset, and drugs used to facilitate endotracheal intubation. Subsequent systematic assessment of readiness for weaning (based on improvement in mental status and suctioning requirements) and downsizing, capping, and decannulation of tracheostomy was performed by the procedural team for the duration of the inpatient stay, although a specific protocol was not used. Responsibility for tracheostomy management and removal was assumed by 
the providers at the rehabilitation or nursing facility the patient was transferred to following discharge.

Timing of percutaneous endoscopic gastrostomy (PEG) was highly variable; it was sometimes performed in the ICU around the time of tracheostomy and often deferred until a later time point, following several weeks of nutrition using transnasal feeding tubes. Given the variability in PEG tube use, and limited data available on timing of PEG tube removal following discharge, we were unable to systematically analyze long-term PEG tube usage and removal.

\section{Functional Outcome Assessment}

Functional endpoints were assessed at 1-3 months, 6-12 months, 12-24 months, and 24-36 months following injury. Follow-up beyond 36 months was included in the last category. Functional outcome assessment at discharge was not considered useful (as opposed to assessment at specific time periods from injury), since patients were frequently discharged to long-term acute care facilities soon after tracheostomy in order to facilitate weaning off mechanical ventilation. Patients were then often brought back to our institution for inpatient rehabilitation or for followup in the ambulatory setting. Specific endpoints assessed included the need for mechanical ventilation, presence of tracheostomy, ability to walk independently (with or without assistive device), and the ability to perform B-ADLs. We also assessed the GCS score at 1-3 months. This information was not part of the database and was abstracted from inpatient and clinic notes of physical therapists, occupational therapists, and physical medicine and rehabilitation providers. Independence in ambulation was defined as a Functional Independence Measure (FIM) score of 5 or greater for locomotion/household ambulation in the physical therapist's note. ${ }^{5,8}$ Independence with respect to B-ADLs was defined as an FIM score of 5 or greater for the specific tasks of dressing, eating, ambulation, toileting, and bathing in the occupational therapist's note. ${ }^{5,8}$ For patients deemed ineligible for therapy, functional status was estimated from neurosurgery and vascular neurology clinic notes. Patients judged to have insufficient documentation of functional ability related to the milestones of interest during a follow-up visit were deemed to not have had follow-up at that time point for the purposes of this study, even if a clinic visit did occur. Modified Rankin Scale (mRS) ${ }^{33}$ and Glasgow Outcome Scale (GOS) $)^{15}$ scores were estimated at the time of each follow-up. We selected the ability to walk and perform B-ADLs as primary outcome measures, rather than the mRS or GOS score, because of the difficulty with determination of the ability to "look after one's own affairs without assistance" (mRS score 2 vs 3 ) and "... help with daily living" (GOS score 3 vs 4). "Independence in daily living" in these assessment scales-which is distinct from independence in B-ADLs, which we assessed as described above-requires the ability to manage finances, procure food, and/or be employed, all of which are difficult to determine from a retrospective review of documentation. The ability to walk and the ability to perform B-ADLs were therefore selected as outcome measures that could more consistently and accurately be extracted from a review of documentation in the medical record. These outcomes, which approximately correspond to an mRS score of 3 (independent ambulation) and "upper severe disability" on the extended GOS (E-GOS) scale (independence within the home), also frequently serve as thresholds for favorable outcome in clinical trials of severe brain injury. ${ }^{7,14,26}$ Long-term functional recovery (LFR) was defined as recovery of the ability to walk or perform B-ADLs by the 24- to 36-month follow-up. Delayed functional recovery (DFR) was defined as progression in functional milestones between any 2 time points beyond the 1- to 3-month follow-up.

\section{Statistical Analysis}

Descriptive statistics included proportions with percentages for categorical data and medians with interquartile ranges (IQRs) for continuous data. We first described recovery to each major functional milestone-the ability to walk and to perform B-ADLs-at any time, as a proportion of the total initial cohort. All patients lost to follow-up were, therefore, assumed to have died or otherwise not attained the milestone for the purposes of this calculation, which yielded the minimum proportion of 1-month survivors who demonstrated recovery to that specific milestone at any subsequent time. We then also described the proportion of patients with follow-up (including patients known to have died in the denominator) who achieved each milestone at each time point of follow-up (Table 1). Delayed functional recovery was described as the proportion of patients who were alive but had not attained the functional outcome measure (walking or performance of B-ADLs) at a specific time point and had follow-up at the subsequent time period of follow-up, who had achieved the functional outcome measure at the subsequent time period of follow-up. The chi-square or Fisher exact test was used, as appropriate, to test the significance of association between categorical variables. The Mann-Whitney U-test was used to test for statistically significant differences in continuous variables between groups. A p value $<0.05$ was the threshold for statistical significance. Multivariate analysis was performed to study predictors of LFR using binary logistic regression, with age, sex, diagnosis, and GCS score at time of tracheostomy as the explanatory variables. An odds ratio (OR) with $95 \%$ confidence interval $(95 \% \mathrm{CI})$ was calculated for predictors. Multivariate analysis using the same explanatory variables was repeated for the response variable of DFR.

\section{Results}

A total of 144 patients met inclusion criteria. Fifteen were then excluded for having less than 1 month of follow-up. The remaining 129 patients were included in the analysis. The median age of these patients was 57 years (IQR 22 years), and 64 (50\%) were women. The median GCS score at the time of tracheostomy was 7T (IQR 5-7). The median GCS score at 7 days after injury was 7T (IQR 5-9). The median number of days from injury to tracheostomy was 6 (IQR 4-8). The median APACHE-2 score was 19 (IQR 16-21). The diagnoses were as follows: SAH in 50 cases (39\%), ICH in $33(26 \%)$, sTBI in 27 (21\%), and AIS in $19(15 \%)$.

Information on follow-up, death, recovery to specific 
TABLE 1. Milestones of functional recovery at different time periods of follow-up

\begin{tabular}{|c|c|c|c|c|c|c|c|c|c|}
\hline $\begin{array}{l}\text { Time Period } \\
\& \text { Diagnosis }\end{array}$ & $\begin{array}{c}\text { Adequate } \\
\text { Documentation of } \\
\text { Functional Status* }\end{array}$ & $\begin{array}{l}\text { Median No. of } \\
\text { Days to } \\
\text { Follow-Up (IQR) }\end{array}$ & $\begin{array}{l}\text { Median } \\
\text { mRS } \\
(I Q R)\end{array}$ & $\begin{array}{l}\text { Median } \\
\text { GOS } \\
(\mathrm{IQR})\end{array}$ & Dead $†$ & $\begin{array}{l}\text { Mechanical } \\
\text { Ventilation } \\
\text { Required }\end{array}$ & $\begin{array}{c}\text { Tracheostomy } \\
\text { Present }\end{array}$ & $\begin{array}{l}\text { Able to Walk } \\
\text { Independently }\end{array}$ & $\begin{array}{l}\text { Able to } \\
\text { Perform } \\
\text { B-ADLs }\end{array}$ \\
\hline \multicolumn{10}{|l|}{$1-3 \mathrm{mos}$} \\
\hline All diagnoses & 129 & $44(34-59)$ & $4(4-4)$ & $3(3-3)$ & 20 & $5(4 \%)$ & $61(47 \%)$ & $23(18 \%)$ & $3(2 \%)$ \\
\hline sTBI & 27 & $44(38-59)$ & $4(3-4)$ & $3(3-3)$ & 5 & $1(4 \%)$ & $12(44 \%)$ & $7(26 \%)$ & $2(7 \%)$ \\
\hline $\mathrm{SAH}$ & 50 & $48(34-62)$ & $4(3-4)$ & $3(3-3)$ & 6 & $0(0 \%)$ & $20(40 \%)$ & $13(26 \%)$ & $1(2 \%)$ \\
\hline $\mathrm{ICH}$ & 33 & $39(33-56)$ & $4(4-4)$ & $3(3-3)$ & 5 & $3(9 \%)$ & $20(61 \%)$ & $3(9 \%)$ & $0(0 \%)$ \\
\hline AIS & 19 & $43(34-65)$ & $4(4-4)$ & $3(3-3)$ & 4 & $1(5 \%)$ & $9(26 \%)$ & $0(0 \%)$ & $0(0 \%)$ \\
\hline \multicolumn{10}{|l|}{$6-12$ mos } \\
\hline All diagnoses & 97 & 226 (187-271) & $3(1-4)$ & $3(3-5)$ & 31 & $0(0 \%)$ & $1(1 \%)$ & $47(48 \%)$ & $31(32 \%)$ \\
\hline sTBI & 18 & $224(212-264)$ & $3(1-4)$ & $4(3-5)$ & 6 & $0(0 \%)$ & $1(6 \%)$ & $8(44 \%)$ & $5(28 \%)$ \\
\hline $\mathrm{SAH}$ & 38 & 224 (177-257) & $2(1-3)$ & $4(3-5)$ & 9 & $0(0 \%)$ & $0(0 \%)$ & $25(66 \%)$ & $19(50 \%)$ \\
\hline $\mathrm{ICH}$ & 24 & $234(175-326)$ & $3(2-4)$ & $3(3-4)$ & 10 & $0(0 \%)$ & $0(0 \%)$ & $9(38 \%)$ & $5(21 \%)$ \\
\hline AIS & 17 & $238(208-320)$ & $4(3-4)$ & $3(3-3)$ & 6 & $0(0 \%)$ & $0(0 \%)$ & $5(29 \%)$ & $2(12 \%)$ \\
\hline \multicolumn{10}{|l|}{$12-24$ mos } \\
\hline All diagnoses & 83 & $472(400-606)$ & $2(1-3)$ & $4(3-5)$ & 32 & $0(0 \%)$ & $1(1 \%)$ & $41(49 \%)$ & $35(42 \%)$ \\
\hline sTBI & 17 & $465(412-604)$ & $1(1-2)$ & $5(3-5)$ & 6 & $0(0 \%)$ & $1(6 \%)$ & $9(53 \%)$ & $9(53 \%)$ \\
\hline $\mathrm{SAH}$ & 32 & $571(407-658)$ & $2(1-3)$ & $4(3-5)$ & 9 & $0(0 \%)$ & $0(0 \%)$ & $21(66 \%)$ & $17(53 \%)$ \\
\hline $\mathrm{ICH}$ & 20 & $414(394-533)$ & $3(2-4)$ & $4(3-4)$ & 10 & $0(0 \%)$ & $0(0 \%)$ & $7(35 \%)$ & $6(30 \%)$ \\
\hline AIS & 14 & $428(371-568)$ & $3(2-4)$ & $3(3-5)$ & 7 & $0(0 \%)$ & $0(0 \%)$ & $4(29 \%)$ & $3(21 \%)$ \\
\hline \multicolumn{10}{|l|}{$24-36$ mos } \\
\hline All diagnoses & 80 & $992(828-1078)$ & $2(1-3)$ & $4(3-5)$ & 33 & $0(0 \%)$ & $1(1 \%)$ & $38(48 \%)$ & $34(43 \%)$ \\
\hline sTBI & 17 & $845(766-1204)$ & $2(1-2)$ & $5(3-5)$ & 6 & $0(0 \%)$ & $1(1 \%)$ & $9(53 \%)$ & $9(53 \%)$ \\
\hline $\mathrm{SAH}$ & 29 & $1009(828-1075)$ & $1(1-2)$ & $5(4-5)$ & 10 & $0(0 \%)$ & $0(0 \%)$ & $18(62 \%)$ & $17(59 \%)$ \\
\hline $\mathrm{ICH}$ & 19 & $986(828-1068)$ & $3(2-4)$ & $3(3-5)$ & 10 & $0(0 \%)$ & $0(0 \%)$ & $7(37 \%)$ & $6(32 \%)$ \\
\hline AIS & 15 & $1016(839-1120)$ & $4(2-4)$ & $3(3-5)$ & 7 & $0(0 \%)$ & $0(0 \%)$ & $4(27 \%)$ & $2(13 \%)$ \\
\hline
\end{tabular}

Values represent numbers of patients unless otherwise indicated.

* Including death.

$\dagger$ Number of patients who were dead at the follow-up time specified (cumulative).

milestones, and median mRS and GOS scores at different time points is shown in Table 1.

\section{Death and Follow-Up}

Of 129 patients, 20 (16\%) had died at 1-3 months of follow-up. Of the remaining 109 , by $6-12$ months, 32 (29\%) were lost to follow-up and $11(10 \%)$ had died. Of the remaining 66, at 12-24 months, a further $15(23 \%)$ were lost to follow-up and 1 (2\%) had died. Finally, at 24-36 months, of the remaining 50, $7(14 \%)$ were lost to followup, and $1(2 \%)$ had died.

\section{Mechanical Ventilation and Need for Tracheostomy}

Five (4\%) patients were dependent on mechanical ventilation and $61(47 \%)$ had a tracheostomy at the 1-3 month follow-up assessment. There was no significant difference between diagnoses in the need for mechanical ventilation $(\mathrm{p}=0.4)$ or tracheostomy $(\mathrm{p}=0.34)$ at this time point. At all subsequent time points, no patient was dependent on mechanical ventilation and only a single patient with sTBI required tracheostomy, present at 3 years. The median duration from tracheostomy to decannulation was 34 days (IQR 21-53 days).

\section{mRS and GOS Scores}

There was no statistically significant difference in either score at any time point between patients with sTBI and those with stroke. There was also no difference in median scores between pairings of individual diagnoses at any time point with the following exceptions. Compared to ICH patients, those with SAH had a significantly lower median mRS score at 6-12 months $(\mathrm{p}=0.031)$ and 24-36 months $(p=0.015)$. Also, compared to AIS patients, those with SAH had a significantly lower median $\mathrm{mRS}$ score at 6-12 months $(\mathrm{p}=0.001)$ and $24-36$ months $(\mathrm{p}=0.008)$, and a lower median GOS score at 6-12 months $(\mathrm{p}=0.016)$ and $24-36$ months $(\mathrm{p}=0.021)$.

\section{Ability to Walk Unassisted}

Overall, 59 (46\%) of the original cohort of 129 patients regained the ability to walk (at any time). There was no significant difference between sTBI and stroke at any time point. In multivariate analysis, younger age $(\mathrm{p}=0.000013$, OR $0.93,95 \%$ CI $0.91-0.96)$, male sex $(\mathrm{p}=0.02$, OR 3.07, 95\% CI 1.20-7.89), higher GCS score at time of tracheostomy ( $\mathrm{p}=0.016$, OR $1.50,95 \%$ CI 1.08-2.08), and a diagnosis of SAH ( $\mathrm{p}=0.019$, OR 4.63, 95\% CI 1.29-16.56) 
TABLE 2. Delayed functional recovery: ability to walk

\begin{tabular}{|c|c|c|c|c|c|}
\hline Description & All Diagnoses & sTBI & $\mathrm{SAH}$ & $\mathrm{ICH}$ & AIS \\
\hline Alive but unable to walk unassisted at $1-3$ mos, follow-up available at $6-12$ mos & 58 & 7 & 21 & 17 & 13 \\
\hline $\begin{array}{l}\text { Unable to walk unassisted at } 1-3 \text { mos but able to walk by } 6-12 \text { mos' follow-up (\% } \\
\text { of survivors w/ follow-up) }\end{array}$ & $29(50 \%)$ & $3(43 \%)$ & $14(67 \%)$ & $7(41 \%)$ & $5(38 \%)$ \\
\hline Alive but unable to walk unassisted at $6-12$ mos, follow-up available at $12-24$ mos & 16 & 4 & 4 & 3 & 5 \\
\hline $\begin{array}{l}\text { Unable to walk unassisted at } 6-12 \text { mos but able to walk by } 12-24 \text { mos' follow-up } \\
\text { (\% of survivors w/ follow-up) }\end{array}$ & $5(31 \%)$ & $2(50 \%)$ & $2(50 \%)$ & $0(0 \%)$ & $1(20 \%)$ \\
\hline Alive but unable to walk unassisted at $12-24$ mos, follow-up available at $24-36$ mos & 9 & 1 & 2 & 3 & 3 \\
\hline $\begin{array}{l}\text { Unable to walk unassisted at } 12-24 \text { mos but able to walk by } 24-36 \text { mos' follow-up } \\
\text { (\% of survivors w/ follow-up) }\end{array}$ & $1(11 \%)$ & $0(0 \%)$ & $0(0 \%)$ & $1(33 \%)$ & $0(0 \%)$ \\
\hline
\end{tabular}

were independent predictors of the ability to walk at any time. Three $(33 \%)$ of 9 patients with a GCS score of 3T off all sedation at the time of tracheostomy recovered the ability to walk at any time. Four of 8 patients with a GCS motor score $<4$ at 1-3 months' follow-up had subsequent follow-up. All but one of these had died. The last patient, who had sTBI, was in a minimally conscious state 3 years following injury.

\section{Ability to Perform B-ADLs}

Overall, $48(37 \%)$ of the original cohort of 129 patients regained the ability to perform B-ADLs at any time point. Patients with sTBI were more likely to perform B-ADLs than those with stroke at $1-3$ months $(p=0.049)$, but there was no statistically significant difference at any other time point. In multivariate analysis, younger age $(\mathrm{p}=0.000048$, OR $0.94,95 \%$ CI $0.92-0.97$ ) and higher GCS at time of tracheostomy $(\mathrm{p}=0.019$, OR $1.49,95 \%$ CI 1.07-2.07) were independent predictors of the ability to perform B-ADLs at any time. Two (22\%) of 9 patients with a GCS score of $3 \mathrm{~T}$ off all sedation at the time of tracheostomy recovered the ability to perform B-ADLs at any time.

\section{Delayed Functional Recovery}

Overall, DFR of the ability to walk occurred in 35 (27\%) of the original cohort of 129 patients and ability to perform B-ADLs in $43(33 \%)$. The proportion of survivors with follow-up in each diagnosis category who demonstrated DFR in the ability to walk between specific time periods is shown in Table 2 , and the proportion who demonstrated DFR in ability to perform B-ADLs is shown in Table 3. There was no significant difference in rates of DFR between the broad categories of STBI and stroke at any time point. In multivariate analysis, younger age $(\mathrm{p}=0.003$, OR $0.96,95 \%$ CI $0.93-0.99)$ and a diagnosis of SAH ( $\mathrm{p}=0.03, \mathrm{OR} 4.47,95 \% \mathrm{CI} 1.15-17.41)$ were independent predictors of DFR of the ability to walk at any time, while younger age $(\mathrm{p}=0.001$, OR 95\% CI 0.96 , $0.93-0.98)$ and a diagnosis of SAH $(\mathrm{p}=0.03$, OR 3.97, 95\% CI 1.16-13.60) were independent predictors of DFR of the ability to perform B-ADLs at any time.

\section{Discussion}

In this retrospective longitudinal study of patients with acute severe brain injury who were dependent on an artificial airway and artificial nutrition at the time of transfer out of the ICU, $46 \%$ of the original cohort regained the ability to walk by 24-36 months after the initial injury, while $37 \%$ regained the ability to perform B-ADLs. There was no significant difference in rates of LFR between patients with cerebrovascular injury and those with traumatic injury. Among survivors, delayed functional recovery beyond 1-3 months (50\% and 38\%, respectively, for the ability to walk and perform B-ADLs) - and beyond even 6-12 months (31\% and 43\%, respectively, for the ability to walk and perform B-ADLs) - was common, with rates that did not differ significantly between patients with traumatic and cerebrovascular injury. Patients with SAH were overall more likely to demonstrate both LFR and DFR, compared to patients with ICH or AIS. Other predictors

TABLE 3. Delayed functional recovery: ability to perform B-ADLs

\begin{tabular}{|c|c|c|c|c|c|}
\hline Description & All Diagnoses & sTBI & $\mathrm{SAH}$ & $\mathrm{ICH}$ & AIS \\
\hline Alive but unable to perform B-ADLs at $1-3$ mos, follow-up available at $6-12$ mos & 74 & 11 & 31 & 19 & 13 \\
\hline $\begin{array}{l}\text { Unable to perform B-ADLs at } 1-3 \text { mos but able to perform B-ADLs by } 6-12 \text { mos' } \\
\text { follow-up (\% of survivors w/ follow-up) }\end{array}$ & $28(38 \%)$ & $3(27 \%)$ & $18(58 \%)$ & $5(26 \%)$ & $2(15 \%)$ \\
\hline Alive but unable to perform B-ADLs at $6-12$ mos, follow-up available at $12-24$ mos & 30 & 6 & 10 & 6 & 8 \\
\hline $\begin{array}{l}\text { Unable to perform B-ADLs at } 6-12 \text { mos but able to perform B-ADLs by } 12-24 \text { mos' } \\
\text { follow-up (\% of survivors w/ follow-up) }\end{array}$ & $13(43 \%)$ & $4(67 \%)$ & $4(40 \%)$ & $2(33 \%)$ & $3(38 \%)$ \\
\hline Alive but unable to perform B-ADLs at $12-24$ mos, follow-up available at $24-36$ mos & 13 & 1 & 4 & 4 & 4 \\
\hline $\begin{array}{l}\text { Unable to perform B-ADLs at } 12-24 \text { mos but able to perform B-ADLs by } 24-36 \text { mos' } \\
\text { follow-up ( } \% \text { of survivors w/ follow-up) }\end{array}$ & $2(15 \%)$ & $0(0 \%)$ & $1(25 \%)$ & $1(25 \%)$ & $0(0 \%)$ \\
\hline
\end{tabular}


of LFR were, as may be expected, younger age and higher GCS score at the time of tracheostomy. Younger age was also a predictor of DFR. Strengths of our study include the length of follow-up (2-3 years) and the eligibility criteria. These criteria were designed to minimize overestimation of severity of injury as a result of early reversible factors and to select patients whose surrogates were likely committed to the delivery of supportive care for a significant period of time. This addresses a concern about early reversible factors leading to an overestimation of disease severity in prior studies, particularly in patients with poorgrade SAH. ${ }^{34}$ In up to $30 \%$ of SAH cases initially classified as poor grade, the patients' condition may rapidly improve by at least 1 grade with early ventricular drainage, prior to clipping or coiling. 28

Our findings are significant for several reasons. First, they reinforce the evidence that therapeutic nihilism in the context of severe brain injury may not be justified,,$^{10,18}$ provided the ability to perform B-ADLs and ambulate independently are valued as meaningful outcomes by patients, families, and society as a whole. ${ }^{12}$ Our data are potentially valuable for physicians who routinely counsel surrogates of such patients. Since these discussions typically lead to decisions on the continuation or withdrawal of life support measures, the importance of objective, data-driven counseling cannot be overstated. In our experience, families value estimates of both the likelihood and timeline of recovery to the specific milestones evaluated in our study. It is useful, for example, to inform families that most patients who survive their severe brain injury undergo tracheostomy decannulation within 6 months, and generally sooner (median 34 days in our study), when a systematic approach to weaning is used. It is essential to acknowledge the uncertainty involved and the wide range of possible outcomes for an individual patient. It is also important to ascertain, to the best extent possible, the degree of functional recovery an individual patient may consider meaningful while discussing these possible outcomes. Patients' surrogates should be counseled that functional recovery may proceed very slowly in patients with all forms of severe brain injury, sometimes extending beyond a year from injury. The high incidence of DFR following severe stroke also has implications for outcome assessment in clinical trials. Since DFR after sTBI is well described, ${ }^{1,11,13,17,19,21,29,31}$ outcome assessments in clinical trials involving patients with sTBI are routinely performed at 6 months or a year, ${ }^{4,6,14}$ in contrast to clinical trials for stroke, where outcome assessments are typically performed at 3 months..$^{2,3,7,20}$ Our findings, and the findings of other investigators, ${ }^{23,24,35}$ suggest that routine outcome assessment at 6-12 months should be considered in clinical trials of interventions, such as decompressive craniectomy and tracheostomy, performed in patients with severe stroke. The investigators of the ongoing SETPOINT-2 clinical trial of early vs late tracheostomy in stroke have, for this reason, chosen a 6-month primary outcome measure (NCT02377167; clincaltrials.gov).

Other investigators have reported findings consistent with ours. In a study of 36 patients in a vegetative or minimally conscious state who were admitted to a special rehabilitation center, over $40 \%$ regained the ability perform B-ADLs at 1 year. ${ }^{17}$ In one study of patients with sTBI who required decompressive craniectomy, $48 \%$ demonstrated improvement in the GOS score between 6 and 18 months. ${ }^{11}$ In the Copenhagen Stroke Study, AIS and ICH patients with mild or moderate injury demonstrated a plateau in functional recovery within 8.5 and 13 weeks, respectively, whereas patients with severe AIS/ICH continued to demonstrate functional recovery by 20 weeks. ${ }^{16}$ Studies of patients with poor-grade SAH enrolled in the Barrow Ruptured Aneurysm Trial (BRAT) ${ }^{35}$ and from the University of California, San Francisco, ${ }^{24}$ have shown rates of functional recovery of $61 \%$ and $57 \%$, respectively, between discharge and 6 months. In BRAT, 18\% demonstrated DFR between 6 and 12 months, and 19\% demonstrated DFR between 12 and 36 months. Another study of poor-grade $\mathrm{SAH}$ from Columbia University found improvements in multiple domains between 3 and 12 months after injury. ${ }^{23}$ While these studies, like ours, demonstrated the potential for LFR and DFR in poor-grade SAH, a key distinction is that all patients judged to have a poor grade at admission were included in these studies, while patients in our cohort had both a severe initial grade of injury and also did not show rapid improvement following resolution of rapidly reversible factors in the first few days.

Our study has several limitations. The assessments of functional outcome were retrospective and restricted to relatively crude measures-the ability to walk and perform B-ADLs. We could not assess measures of cognitive outcome or quality of life. Our findings are, therefore, most relevant to patients and surrogates who consider the ability to perform B-ADLs and ambulate to represent an acceptable quality of life. There was significant loss to follow-up, as might be expected in a retrospective study. Assuming the most pessimistic outcome for all patients who were lost to follow-up (death or failure to attain the specific functional milestone), however, $46 \%$ of the original cohort of 129 patients regained the ability to walk and $37 \%$ regained the ability to perform B-ADLs at some point in a 3 -year period following injury. Similarly, assuming every patient lost to follow-up had a bad outcome, DFR was seen in $27 \%$ of the original cohort of 129 for the ability to walk, and $33 \%$ for the ability to perform B-ADLs. Some patients with severe brain injury may have undergone early withdrawal of life-sustaining therapy and would therefore not have been included in our study. Nevertheless, our focus was on patients whose surrogates had committed to the provision of supportive care beyond the ICU stay. Tracheostomy was performed a median of 6 days after injury. Patients were required to have a GCS score $<9$ at the time of tracheostomy to be included in the study, however, and the median duration from tracheostomy to decannulation, with a systematic approach to weaning assessment, was 34 days, suggesting that in general tracheostomy was not performed prematurely and disease severity was not overestimated. We included patients with 4 different types of severe brain injury in our study; therefore the applicability of our findings to individual diseases-particularly AIS, which was relatively underrepresented-is limited. While our study does demonstrate that both LFR and DFR occur commonly among severely injured patients requiring tracheostomy in all 4 disease states, larger cohorts with prospective evaluation of outcomes are necessary to more 
accurately establish specific rates of recovery in individual diseases. Ongoing clinical trials of tracheostomy in severe brain injury may prove useful in this regard (NCT02377167; clincaltrials.gov). Our data may be most applicable to $\mathrm{SAH}$, as an individual disease state, since we had a plurality of patients with this condition in our study $(n=50)$. Since SAH patients overall were more likely to demonstrate both LFR and DFR compared to patients with ICH or AIS, and SAH accounted for most cases of cerebrovascular disease (49\%) in our study, much of the equivalence in LFR and DFR between sTBI and stroke may have been driven by this population. It is nevertheless noteworthy that a substantial proportion of AIS and ICH patients also demonstrated LFR and DFR (Tables 1-3). Finally, documentation was insufficient for us to estimate time to removal of feeding tubes.

In conclusion, among patients with severe brain injury requiring tracheostomy and tube feeding at the time of ICU discharge, about $46 \%$ had regained the ability to walk and $37 \%$ had regained the ability to perform B-ADLs 2-3 years after injury. Delayed functional recovery beyond $1-3$ months as well as beyond 6-12 months was common, with no significant difference between traumatic and cerebrovascular etiologies.

\section{References}

1. Andelic N, Hammergren N, Bautz-Holter E, Sveen U, Brunborg C, Røe C: Functional outcome and health-related quality of life 10 years after moderate-to-severe traumatic brain injury. Acta Neurol Scand 120:16-23, 2009

2. Anderson CS, Heeley E, Huang Y, Wang J, Stapf C, Delcourt $\mathrm{C}$, et al: Rapid blood-pressure lowering in patients with acute intracerebral hemorrhage. N Engl J Med 368:2355-2365, 2013

3. Berkhemer OA, Fransen PS, Beumer D, van den Berg LA, Lingsma HF, Yoo AJ, et al: A randomized trial of intraarterial treatment for acute ischemic stroke. N Engl J Med 372:11-20, 2015

4. Chesnut RM, Temkin N, Carney N, Dikmen S, Rondina C, Videtta W, et al: A trial of intracranial-pressure monitoring in traumatic brain injury. N Engl J Med 367:2471-2481, 2012

5. Chumney D, Nollinger K, Shesko K, Skop K, Spencer M, Newton RA: Ability of Functional Independence Measure to accurately predict functional outcome of stroke-specific population: systematic review. J Rehabil Res Dev 47:17-29, 2010

6. Cooper DJ, Rosenfeld JV, Murray L, Arabi YM, Davies AR, D'Urso P, et al: Decompressive craniectomy in diffuse traumatic brain injury. N Engl J Med 364:1493-1502, 2011 (Erratum in N Engl J Med 365:2040, 2011)

7. Frontera JA, Fernandez A, Schmidt JM, Claassen J, Wartenberg KE, Badjatia N, et al: Defining vasospasm after subarachnoid hemorrhage: what is the most clinically relevant definition? Stroke 40:1963-1968, 2009

8. Furlan JC, Noonan V, Singh A, Fehlings MG: Assessment of disability in patients with acute traumatic spinal cord injury: a systematic review of the literature. J Neurotrauma 28:1413-1430, 2011

9. Go AS, Mozaffarian D, Roger VL, Benjamin EJ, Berry JD, Borden WB, et al: Heart disease and stroke statistics-2013 update: a report from the American Heart Association. Circulation 127:e6-e245, 2013

10. Hemphill JC III, White DB: Clinical nihilism in neuroemergencies. Emerg Med Clin North Am 27:27-37, vii-viii, 2009
11. Ho KM, Honeybul S, Litton E: Delayed neurological recovery after decompressive craniectomy for severe nonpenetrating traumatic brain injury. Crit Care Med 39:2495-2500, 2011

12. Honeybul S, Ho KM, Gillett GR: Long-term outcome following decompressive craniectomy: an inconvenient truth? Curr Opin Crit Care 24:97-104, 2018

13. Hoofien D, Gilboa A, Vakil E, Donovick PJ: Traumatic brain injury (TBI) 10-20 years later: a comprehensive outcome study of psychiatric symptomatology, cognitive abilities and psychosocial functioning. Brain Inj 15:189-209, 2001

14. Hutchinson PJ, Kolias AG, Timofeev IS, Corteen EA, Czosnyka M, Timothy J, et al: Trial of decompressive craniectomy for traumatic intracranial hypertension. N Engl J Med 375:1119-1130, 2016

15. Jennett B, Bond M: Assessment of outcome after severe brain damage. Lancet 1:480-484, 1975

16. Jørgensen HS, Nakayama H, Raaschou HO, Vive-Larsen J, Støier M, Olsen TS: Outcome and time course of recovery in stroke. Part II: Time course of recovery. The Copenhagen Stroke Study. Arch Phys Med Rehabil 76:406-412, 1995

17. Katz DI, Polyak M, Coughlan D, Nichols M, Roche A: Natural history of recovery from brain injury after prolonged disorders of consciousness: outcome of patients admitted to inpatient rehabilitation with 1-4 year follow-up. Prog Brain Res 177:73-88, 2009

18. Kaufmann MA, Buchmann B, Scheidegger D, Gratzl O, Radü EW: Severe head injury: should expected outcome influence resuscitation and first-day decisions? Resuscitation 23:199-206, 1992

19. Lippert-Grüner M, Lefering R, Svestkova O: Functional outcome at 1 vs. 2 years after severe traumatic brain injury. Brain Inj 21:1001-1005, 2007

20. Macdonald RL, Higashida RT, Keller E, Mayer SA, Molyneux A, Raabe A, et al: Clazosentan, an endothelin receptor antagonist, in patients with aneurysmal subarachnoid haemorrhage undergoing surgical clipping: a randomised, doubleblind, placebo-controlled phase 3 trial (CONSCIOUS-2). Lancet Neurol 10:618-625, 2011

21. Masel BE, DeWitt DS: Traumatic brain injury: a disease process, not an event. J Neurotrauma 27:1529-1540, 2010

22. McCredie VA, Alali AS, Xiong W, Rubenfeld GD, Cuthbertson BH, Scales DC, et al: Timing of withdrawal of life-sustaining therapies in severe traumatic brain injury: Impact on overall mortality. J Trauma Acute Care Surg 80:484-491, 2016

23. Mocco J, Ransom ER, Komotar RJ, Sergot PB, Ostapkovich N, Schmidt JM, et al: Long-term domain-specific improvement following poor grade aneurysmal subarachnoid hemorrhage. J Neurol 253:1278-1284, 2006

24. Navi BB, Kamel H, Hemphill JC III, Smith WS: Trajectory of functional recovery after hospital discharge for subarachnoid hemorrhage. Neurocrit Care 17:343-347, 2012

25. Pignat JM, Mauron E, Jöhr J, Gilart de Keranflec'h C, Van De Ville D, Preti MG, et al: Outcome prediction of consciousness disorders in the acute stage based on a complementary motor behavioural tool. PLoS One 11:e0156882, 2016

26. Qureshi AI, Palesch YY, Barsan WG, Hanley DF, Hsu CY, Martin RL, et al: Intensive blood-pressure lowering in patients with acute cerebral hemorrhage. N Engl J Med 375:1033-1043, 2016

27. Rajajee V, Williamson CA, West BT: Impact of real-time ultrasound guidance on complications of percutaneous dilatational tracheostomy: a propensity score analysis. Crit Care 19:198, 2015

28. Ransom ER, Mocco J, Komotar RJ, Sahni D, Chang J, Hahn DK, et al: External ventricular drainage response in poor grade aneurysmal subarachnoid hemorrhage: effect on pre- 
operative grading and prognosis. Neurocrit Care 6:174-180, 2007

29. Sbordone RJ, Liter JC, Pettler-Jennings P: Recovery of function following severe traumatic brain injury: a retrospective 10-year follow-up. Brain Inj 9:285-299, 1995

30. Selassie AW, Zaloshnja E, Langlois JA, Miller T, Jones P, Steiner C: Incidence of long-term disability following traumatic brain injury hospitalization, United States, 2003. J Head Trauma Rehabil 23:123-131, 2008

31. Thomsen IV: Late psychosocial outcome in severe traumatic brain injury. Preliminary results of a third follow-up study after 20 years. Scand J Rehabil Med Suppl 26:142-152, 1992

32. Turgeon AF, Lauzier F, Simard JF, Scales DC, Burns KE, Moore L, et al: Mortality associated with withdrawal of life-sustaining therapy for patients with severe traumatic brain injury: a Canadian multicentre cohort study. CMAJ 183:1581-1588, 2011

33. van Swieten JC, Koudstaal PJ, Visser MC, Schouten HJ, van Gijn J: Interobserver agreement for the assessment of handicap in stroke patients. Stroke 19:604-607, 1988

34. Wang AC, Heros RC: Editorial: Subarachnoid hemorrhage grading scales. J Neurosurg 124:296-298, 2016

35. Wilson DA, Nakaji P, Albuquerque FC, McDougall CG, Zabramski JM, Spetzler RF: Time course of recovery following poor-grade SAH: the incidence of delayed improvement and implications for SAH outcome study design. J Neurosurg 119:606-612, 2013

36. Zaloshnja E, Miller T, Langlois JA, Selassie AW: Prevalence of long-term disability from traumatic brain injury in the civilian population of the United States, 2005. J Head Trauma Rehabil 23:394-400, 2008

\section{Disclosures}

The authors report no conflict of interest concerning the materials or methods used in this study or the findings specified in this paper.

\section{Author Contributions}

Conception and design: Rajajee. Acquisition of data: Rajajee, Wabl, Williamson. Analysis and interpretation of data: Rajajee, Wabl, Pandey. Drafting the article: Rajajee, Wabl. Critically revising the article: all authors. Reviewed submitted version of manuscript: all authors. Approved the final version of the manuscript on behalf of all authors: Rajajee. Statistical analysis: Rajajee, Wabl. Administrative/technical/material support: Rajajee. Study supervision: Rajajee, Pandey.

\section{Supplemental Information}

\section{Previous Presentations}

Early results from this study were presented at the Neurocritical Care Society 11th annual meeting, October 2013, Philadelphia, PA.

\section{Correspondence}

Venkatakrishna Rajajee: University of Michigan, Ann Arbor, MI. vrajajee@yahoo.com. 